Florida International University FIU Digital Commons

11-20-1998

\title{
A comparison of childbirth class attendance and presence at delivery and father-infant acquaintance/attachment
}

Susan Diane Bernath

Florida International University

DOI: $10.25148 /$ etd.FI14051124

Follow this and additional works at: https://digitalcommons.fiu.edu/etd

Part of the Maternal, Child Health and Neonatal Nursing Commons

\section{Recommended Citation}

Bernath, Susan Diane, "A comparison of childbirth class attendance and presence at delivery and father-infant acquaintance/ attachment" (1998). FIU Electronic Theses and Dissertations. 1629.

https://digitalcommons.fiu.edu/etd/1629 


\section{FLORIDA INTERNATIONAL UNIVERSITY}

Miami, Florida

\section{A COMPARISON OF CHILDBIRTH CLASS ATTENDANCE AND PRESENCE AT DELIVERY AND FATHER-INFANT ACQUAINTANCE/ATTACHMENT}

A thesis submitted in partial fulfillment of requirements for the degree of MASTER OF SCIENCE in NURSING

by

Susan Diane Bernath

1998 
To: Dean DeLois P. Weekes

College of Health Sciences

This thesis, written by Susan Diane Bernath, and entitled A Comparison of Childbirth Class Attendance and Presence at Delivery and Father-Infant Acquaintance/Attachment, having been approved in respect to style and intellectual content, is referred to you for judgment.

We have read this thesis and recommend that it be approved.

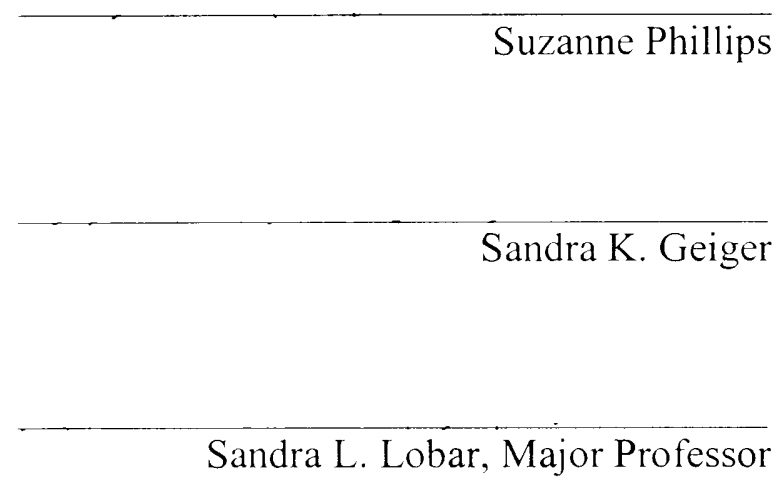

Date of Defense: November 20, 1998

The thesis of Susan Diane Bernath is approved.

Dean DeLois P. Weekes College of Health Sciences

Dean Richard L. Campbell Division of Graduate Studies

Florida International University, 1998 
(C) Copyright 1998 by Susan Diane Bernath

All rights reserved. 


\section{DEDICATION}

I dedicate this thesis to my wonderful family and close friends. Without their patience, understanding, and support, and most of all love, the completion of this work would not have been possible. 


\section{ACKNOWLEDGEMENTS}

I gratefully wish to thank the members of my committee, Dr. Suzanne Phillips and Dr. Sandra Geiger, for their support, encouragement, and patience during this long distance endeavor. Their direction, knowledge, and expertise have greatly enhanced this work.

My gratitude to Dr. Paulette Johnson for her assistance with the statistical analysis. Her guidance and suggestions were invaluable.

I wish to thank Dr. Janice Gay for permission to use her schematic model of the bonding process and to Dr. Myra Leifer for permission to use her $\underline{\text { How I Feel About My }}$ Baby Now tool.

A special word of gratitude to my Major Professor, Dr. Sandra L. Lobar. Her interest, guidance, and dedication to this project have been continuous. I have appreciated her availability and the many contributions she has made to this work. 
ABSTRACT OF THE THESIS

A COMPARISON OF CHILDBIRTH CLASS ATTENDANCE AND

PRESENCE AT DELIVERY AND FATHER-INFANT

ACQUAINTANCE/ATTACHMENT

by

Susan Diane Bernath

Florida International University, 1998

Miami, Florida

Professor Sandra L. Lobar, Major Professor

The relationship between parent and child is one of the most important and most studied of all human relationships. The purpose of this descriptive study was to compare first-time fathers' attendance at an entire series of prepared childbirth classes and presence at the delivery with father-infant acquaintance/attachment at three to four months post-birth. First-time fathers living with the infant's mother were asked to

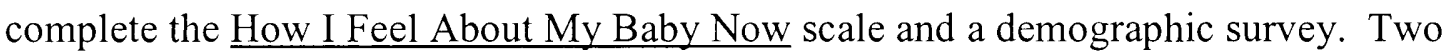
groups of fathers were compared. The first group attended classes, and the other group did not attend classes. Results of a statistical analysis utilizing descriptive statistics, t-tests, and one way ANOVA indicated that fathers who attended the classes felt significantly more angry at their babies than those who did not, and that fathers in the group under 30 years of age felt more playful toward their babies than those over thirty years. 


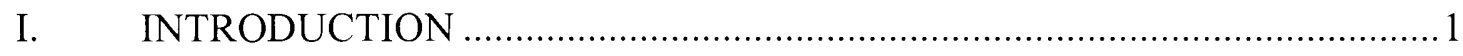

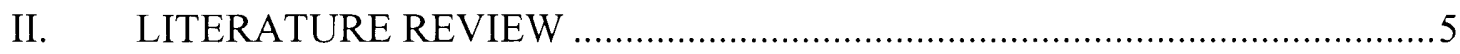

Early Research Related to Acquaintance, Attachment, and Bonding................5

Paternal Acquaintance, Attachment, and Bonding ...................................... 8

Paternal-Fetal Acquaintance and Attachment............................................. 10

Prenatal Class Attendance and Attachment ...................................................12

Birth Attendance Related to Attachment and Bonding....................................13

Prenatal Class Attendance and Birth Attendance ............................................. 14

Paternal Involvement in Infant Care .......................................................... 15

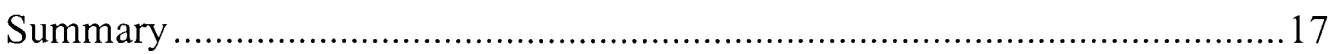

Theoretical Framework ................................................................................... 18

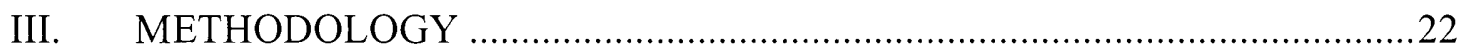

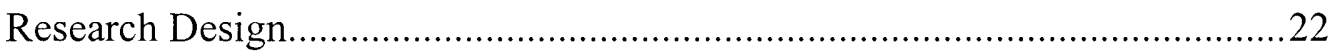

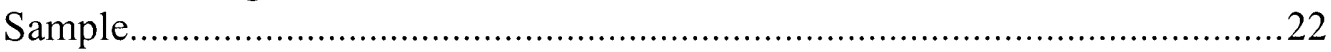

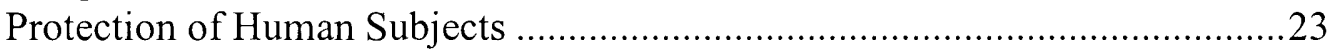

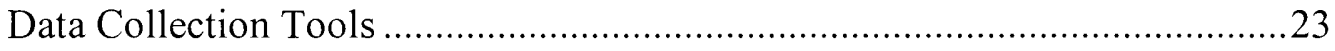

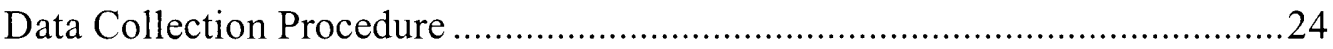

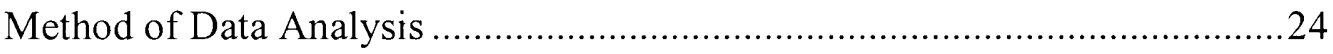

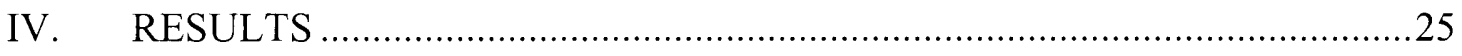

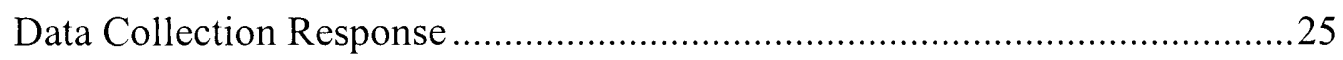

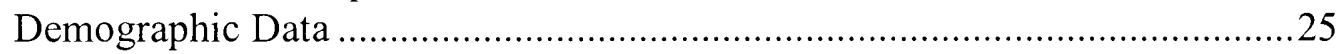

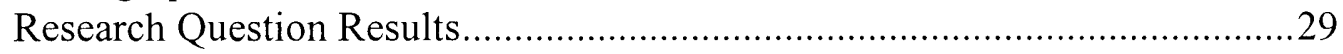

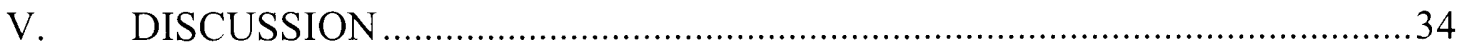

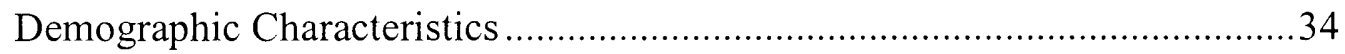

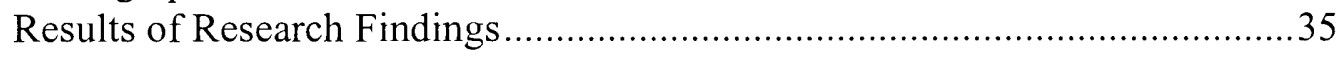

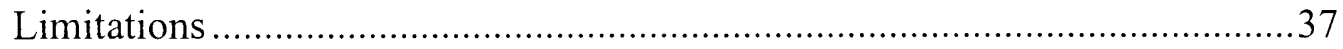

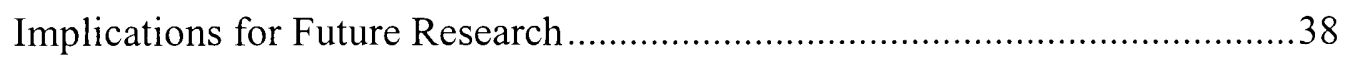

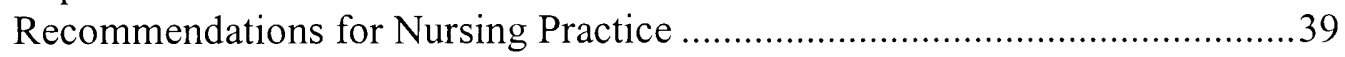

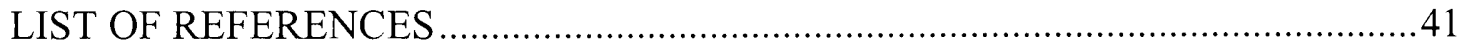

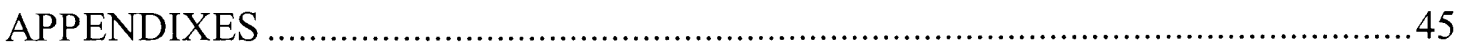


TABLE

PAGE

Table 1: Characteristics of Total Sample by Age and Race

Table 2: Characteristics of Total Sample by Education, Occupation, and Marital Status.

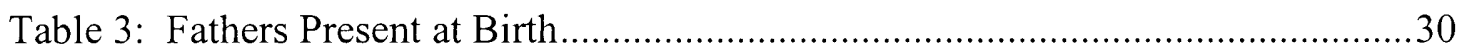

Table 4: Fathers Attending Childbirth Class ........................................................... 31

Table 5: Analysis of FAB Items by Class Attendance …….......................................... 32

Table 6: I Feel Playful FAB Item Analyzed by Age ....................................................33 


\section{Chapter 1}

Introduction

The relationship between parent and child is one of the most important and most studied of all human relationships. Mothering, maternal acquaintance and attachment, and the maternal-infant bond have been subjects of research and study since the 1960's. Rubin $(1967,1984)$ and Mercer (1985) reported on maternal identity and maternal role attainment. Klaus and Kennell (1976) studied maternal-infant interaction and the process of maternal-infant bonding. The concept of fathering, however, and activities that would positively affect father-infant acquaintance and attachment have not been explored as extensively.

\section{Problem Statement}

Margaret Mead (I949) noted that motherhood is a biological necessity, but fatherhood is a social invention. Garbino (1993) explained that Mead meant "parenthood for women is tied to their biological role and that a mother's role is clear, whereas the role of the father is intrinsically ambiguous and relies upon cultural prescription" (p. 51). Historically, parenthood has been quite different for women than for men. The mother's role has been and has remained more traditional over the years, but fatherhood is in the midst of a new and exciting transition.

Fathering responsibilities and society's expectations of fathers' behavior have changed dramatically, especially since family-centered childbirth has become the norm in hospitals and childbirth centers (Brazelton, 1981). Kunst-Wilson and Cronenwett (1981) noted that 'the father's potential contribution to the infant's overall development has been misperceived or devalued and that the father's ability and willingness to assume 
a more active role in the infant's care may have been underestimated" (p. 201). Yet, little research has been done in the area of the father-infant relationship.

A conceptual framework of bonding presented by Gay (1981) proposed that paternal-infant acquaintance and attachment are components of the bonding process. Activities which provide the father with greater involvement in the pregnancy and opportunity for acquaintance and attachment have the potential to promote bonding. Ferketich and Mercer (1995) noted that "after over two decades of parent-infant attachment research, little is known about factors explaining the early development of one of the strongest of all human bonds" (p. 36). Coffman (1992) stated that "nurses are in a critical position to assess parent-infant interactions, to interpret the meaning of infants' behaviors to parents, and to encourage facilitative parenting behaviors" (p. 421). By adding to the growing body of research on the father-infant relationship, it is hoped that father-infant acquaintance and attachment can be better facilitated.

\section{Purpose of Study}

The purpose of this study is to compare first-time father's attendance at an entire series of prepared childbirth classes and presence at the infant's delivery and fatherinfant acquaintance/attachment at three to four months of age.

\section{$\underline{\text { Research Questions }}$}

1. Is there a relationship between the variable of the father's presence at the infant's birth and the variable of father-infant acquaintance/attachment at three to four months of age?

2. Is there a relationship between the variable of the father's participation in an 
entire series of prepared childbirth classes and the variable of father infant acquaintance/ attachment at three to four months of age?

3. How do demographic variables such as age, race, level of education, occupation, and marital status compare with acquaintance/attachment at three to four months of age?

Definition of Terms

1. Father: For the purpose of this study, fathers are those men who are experiencing their first biological child's birth and who are living with the infant's mother.

2. Prepared childbirth class attendance: Attendance at prepared childbirth class is defined as the biological father attending, with the mother, every class of a series covering the process of fetal growth, the process of labor and delivery, and the methods of supporting the mother during labor and delivery. These classes may be sponsored by a public or private group and may be free or paid for by the couple.

3. Presence at birth: Presence at the birth of the infant is defined as the biological father being in the room with the mother as she delivers the couple's infant in either a hospital, childbirth center, or at home.

4. Acquaintance: In this study, acquaintance is defined by Newcomb (1961) as "the foundation of all subsequent relationships, and that an opportunity for a two-way interaction between all indivduals" is necessary for acquaintance to occur (p.5).

5. Attachment: In this study, attachment is defined by Gay (1981) as "the gradual, continuing, reciprocal process that occurs between individuals and incorporates the components of the acquaintance process" (p. 441). 
6. Bonding: In this study, bonding is defined by Gay (1981) as "a gradual, continuing, reciprocal process that incorporates the processes of acquaintance and attachment and links two individuals in a coordinated, constructive social relationship" (p. 442).

\section{Significance of the Study}

In the past, fatherhood encompassed moral teaching, breadwinning, sex-role modeling, and child discipline (Hall, 1994). The role of the father in the family has evolved over recent years. A father is now encouraged to and, for the most part, wants to take a more active role in his infant's growth and development. "Today's fathers are expected to be more actively involved in child care than in the past, and to a modest extent the average contemporary father is indeed more involved than was his predecessor" (Lamb, 1986, p.3). Palkovitz (1980) stated that father-infant attachment and bonding are important to the father in adapting to his new role, and to the infant who needs nurturing to survive.

Activities which will facilitate not only mother-infant, but also father-infant acquaintance/attachment have not previously been explored to a large extent. Becoming a father is a developmental process with which nurses can assist. Nurses interact with couples during the prenatal months and the first few months following delivery. Nurses have the opportunity and responsibility to assess both partners' responses to the pregnancy and to labor and delivery and to provide support and anticipatory guidance along the way. 
Chapter 2

Review of the Literature

This review of the literature describes early research related to acquaintance, attachment, and bonding. The literature review also includes research specifically related to paternal-fetal and paternal-infant acquaintance, attachment, and bonding. Research studies regarding prenatal class attendance and birth attendance are presented along with studies which relate these events to paternal involvement in infant care.

\section{Early Research Related to Acquaintance, Attachment, and Bonding}

Early research on parent-child relationships has focused mainly on mothers in terms of their attachment, bonding, and maternal-child interaction. However, a number of researchers have made reference to fathers or have focused on father-child relations.

John Bowlby (1969) was a significant pioneer in the study of attachment. He initially conducted field studies of ground nesting birds and then other animals and their young in an attempt to understand what he termed "attachment behavior." He defined attachment behavior as actively seeking and maintaining proximity to another individual. Bowlby (1980) stated that "during the course of healthy development, attachment behavior leads to the development of affectional bonds or attachments, initially between child and parent and later between adult and adult" (p. 39). Bowlby's references to fathers, however, are few, and many of his studies compare attachment behavior in humans to that of animals, including sub-human primates.

Bowlby noted that because the human infant is born so immature and is so slow to develop compared to other animals, it takes longer for attachment behavior to appear. He hypothesized that this might be why previous researchers had not realized that 
attachment behavior existed. Bowlby (1977) stated that attachment theory is " a way of conceptualizing the propensity of human beings to make strong affectional bonds to particular others and of explaining the many forms of emotional distress to which unwilling separation and loss give rise" (p. 201).

Ainsworth (1969) studied the development of mother-infant attachment including maternal behaviors. She visited 25 African mothers and their infants several hours a day and found attachment behavior clearly present in the infants by six months of age. Relevant maternal behaviors leading to attachment included close body contact, maternal responsiveness to infant crying, and maternal behavior relevant to feeding. Ainsworth (1973) described attachment as "an affectional tie that one person forms to another specific person, binding them together in space and enduring over time" (p. 1).

Rubin (1967) focused on maternal identity and the maternal experience. This researcher first described the "trying on" of the maternal role. Rubin studied five primagravidas and four multiparas throughout their pregnancies and for the first month postpartum. She observed for verbal and nonverbal behavior in the subjects' actions and interactions by conducting unstructured interviews in the normal clinical setting. Her findings included the "taking in" role of mother, categories of the self-system, operations involved in "becoming" a mother, and the sequence of these operations. Husbands of women involved in the study seemed to do as much role play "as if" they were fathers as their wives did for the role of mother. According to Rubin, replication in mimicry and role play served as a bridge to becoming a parent and were found to be preliminary binding-in of a maternal and paternal identity and attachment. 
Brazelton (1981) studied parent-child interaction by meeting with the couples at what he called "touch points", when the parents were open to outside help. These meetings were held at times when he felt a touch or contact from an understanding observer could give the couple insight or direction and fuel their attachment to one another. Brazelton noted that the father's presence at the prenatal visit, and including him in happenings at that time, assisted him in feeling necessary to the infant's optimal development and ensured future participation. Brazelton stated that "The feelings of being excluded are real ones for a young father in our culture" (p. 15). He noted that at delivery, "with the father present, the couple will have a significantly better chance of becoming a family and of rearing this baby in a more nurturing way" (p. 58).

Klaus and Kennell (1976) were also early investigators of the concept of maternal-infant bonding. They stated that

a mother and father's behavior toward their infant is derived from a complex combination of their own genetic endowments, the infant's responses to them, a long history of interpersonal relations with their own families and with each other, past experiences with this or previous pregnancies, the absorption of the practices and values of their cultures, and probably most importantly, the way in which each was raised by his or her own parents. (p. 12)

Klaus and Kennell (1976) initially reviewed previous ethological field studies and experimental laboratory studies of animal mothers and their offspring Their research in two Guatemala City hospitals encompassed several studies, one of which compared mothers having immediate opportunity to be with their infants with those separated from their infants for 12 hours. One group was given their nude infants to hold under a heat 
lamp, while the control group was not given their infants to breastfeed for 12 hours, the usual routine. At 12 hours, each mother's interactions with her infant were observed during the initial breastfeeding by an investigator who was not aware of the group to which the mother belonged. Significantly more attachment behaviors were shown by the early contact group than the control group. Klaus and Kennell (1982) conducted a number of studies over the following years coining the term "critical period" for the time immediately following birth. The researchers concluded that if the mother and infant failed to form an attachment during this time, situations such as child abuse and failure to thrive could take place. Nelson (1985), in reviewing research related to both animal and human attachment, stated that "The theory of critical periods does not take into account the plasticity of human nature and oversimplifies human behavior" (p. 35). The term was later redefined as a "sensitive period" since Klaus and Kennell acknowledged that many processes acted together to pull the parents and infant together and that humans have many sensitive periods over the life span.

\section{Paternal Acquaintance, Attachment, and Bonding}

Parental acquaintance, attachment, and bonding has been described as a process during which a parent develops a lifetime emotional commitment to an infant and has been observed as a process which occurs over time. Ferketich and Mercer (1995) stated that "parent-infant attachment is a cognitive and social process that develops through positive feedback and satisfying experiences between the attaching dyad" (p. 31). Studies on paternal attachment and bonding began in the middle 1970's but became more frequent in the 1980's and 1990's. 
Mercer and Ferketich (1990) studied 481 subjects for predictors of parental attachment before delivery, during hospitalization, and later following birth. Of the subjects, 121 were high-risk women, 61 were partners of high-risk women, 182 were low-risk women, and 117 were partners of the low-risk women. Subjects were tested antepartally, at one week postpartum, and at one, four, and eight months; only the first week and eight month postpartum results were reported in the study. Results indicated that parental competence was a major predictor of parental attachment over the five test periods of the study. Mercer and Ferketich concluded that "attachment is an interactive process between partners resulting in satisfying experiences and an emotional bond motivating parental commitment to caring for the infant" (p.268).

Cox, Owen, Henderson, and Margand (1992) used a longitudinal study to investigate the first year correlates of infant-father and infant-mother attachment. Parents were interviewed and asked questions concerning their feelings about the infant and the parenting role and perceptions of the child's development. The researchers reported as an important finding that the father's attitude about the infant and his parenting role predicted significant variation in infant-father security of attachment. Cox et al. suggested that looking at the parents' cognitions and reports about the infant and the parental role may be important in an understanding of the development of the infant-father relationship.

Palkovitz (1992) studied changes in father-infant bonding beliefs across a couple's first transition to parenthood and noted that both prenatal beliefs and circumstances of the delivery predict changes in father-infant bonding beliefs. Before delivery, both fathers and mothers demonstrated moderately strong beliefs about 
the importance of father-infant bonding. However, by three weeks postpartum, both mothers and fathers indicated significant drops in father-infant bonding belief scores as characterized by ambivalence about father-infant bonding. Palkovitz noted that the couples were not dissatisfied with their birth experience, but that their convictions about the importance of father-infant bonding were not as strong. He stated two alternative explanations for this might be that new parents were disappointed in the importance of father-infant bonding or that the impact of the immediate postpartum period had dulled in comparison to the salience of ongoing events of daily interaction.. He concluded that, especially for the group of fathers with strong beliefs about the necessity of father-infant bonding, "a longer initial contact in the presence of the mother and a number of supportive staff appears to enhance fathers' evaluation of the bonding experience as important" (p. 153).

\section{$\underline{\text { Paternal-Fetal Acquaintance and Attachment }}$}

The relationship between expectant parents and the fetus has been one of the most important research areas into the dynamics of pregnancy. Weaver and Cranley (1982) tested 100 fathers who had wives in the third trimester of pregnancy to explore the attachment process between father and fetus. Using the Maternal-Fetal Attachment Scale, the Marital Relationship Scale, and the Physical History Scale, a 63 item questionnaire was administered in various childbirth education classes. Research supported the belief that expectant fathers demonstrate attachment behaviors toward the fetus during gestation. In response to individual items, $93 \%$ of the subjects said they were really looking forward to seeing what the baby looked like and $85 \%$ felt the trouble 
of being pregnant was worth it.

May (1982) conducted a field study involving intensive interviews with 20 expectant couples and short field interviews with an additional 80 fathers. The study focused on the social-psychological experience of first-time expectant fatherhood and the progression of pregnancy from the father's perspective. May found that emotional involvement developed among first-time fathers over three phases referred to as announcement, moratorium, and focusing. While in the announcement phase, most of the men either noticed or were advised about early signs of their partners' pregnancies, but lagged behind them in their involvement. During the moratorium, the men removed pregnancy from their consciousness since it was unreal to them. The end of the moratorium usually tended to be near the end of the 25 th week when the pregnancy became more visible. The focusing phase marked the end of the "not real"--"not mine" character of the moratorium phase. It was May's suggestion that the speed at which the man progressed through these three phases could affect adjustment to fatherhood.

Jordan (1990) used grounded theory to gather and analyze data from 56 new and expectant first-time fathers. More than 180 audiotaped interviews lasting from 0.5 to 2.5 hours each served as the data base for this study. The results of the study reinforced previous findings that the mother has a role in promoting paternal behavior and controlling the degree to which the pregnancy is shared. This was not seen as a malicious or purposeful exclusion, but as benign societal neglect. Fathers indicated that partners, friends, family, and health care professionals viewed them only in a supportive way. Men in this study wanted to be involved parents, but they felt they did not have the skills, knowledge, or support to do so. Some men did not actually begin to feel 
responsible for their infants' care until they experienced the reality of fathering (Henderson \& Brouse, 1991; Jordan, 1990).

Sandelowski and Black (1994) conducted 288 interviews with 62 white, married, middle class couples during pregnancy and postdelivery using Guba's paradigm dialogue. The researchers described the epistemological relationship between parents and fetus emphasizing fetal acquaintanceship as distinguished from fetal attachment. Epistemology is concerned with issues regarding the knowing relationship between the knower and the knowable. Usually during pregnancy there are two knowers (the mother and typically a male partner) and a changing knowable (the fetus). Sandelowski and Black found no uniform, linear progression evident in the development of relations to the fetus that clearly corresponded to the biological progression of pregnancy. The researchers also found a lack of clarity about the relationship between fetal acquaintanceship and fetal attachment. Some activities viewed as indicators of attachment might actually be the parent's efforts to acquire knowledge about the baby. Prenatal Class Attendance and Attachment

A pilot study by Bowen and Miller (1980) explored father-infant attachment and its relationship to pre-parenthood classes, presence at delivery, and infant state. A group of 48 fathers and their infants were studied between 12 and 48 hours after delivery. Observations were made of the fathers without knowing whether the fathers had attended pre-parenthood classes or had been present at the delivery. Presence at delivery was shown to be an important variable related to observable attachment behaviors of fathers of newborn infants. Fathers present at delivery looked at and talked to their infants more 
than fathers who were not present at delivery. Pre-parenthood classes were not found to be significant in regard to fathers' attachment behaviors. A limitation of the study was that subjects self-selected rather than being randomly assigned into groups since they themselves made the decision to attend the classes and/or to present at delivery. The authors suggested that longitudinal studies were needed to determine the significance of father-infant interaction.

\section{Birth Attendance Related to Attachment and Bonding}

A labor coach, most often the infant's father, often accompanies the woman during childbirth. Motives, beliefs, and expectations about birth attendance may vary widely depending upon culture, knowledge base, experience, and age.

Palkovitz (1985) reviewed the results of 8 studies of birth attendance by fathers. He found that the factors of birth attendance and early or extended contact with their newborns had no conclusive effects on father-infant bonding. In other research, Palkovitz (1987) studied 37 couples expecting their first child using open-ended interviews and questionnaires. Data was collected during the third trimester of pregnancy, but before childbirth education classes had begun. His research concerning fathers' motives for birth attendance confirmed that a majority of both mothers and fathers felt that attending the birth would cause the father to have a closer relationship with his child, make the father better able to express tender and affectionate feelings toward the baby, and make a difference to the child that his/her father was at the birth. The research also confirmed that both mothers and fathers felt that attending the birth would make it easier for the father to be involved in the daily care of the child, make it clear to the father that he is a parent, and cause the father to realize the responsibilities of 
fatherhood.

Prenatal Class Attendance and Birth Attendance

Miller and Bowen (1982) studied father-infant bonding in relation to both prenatal class attendance and presence at delivery. They hypothesized that fathers who had both of these experiences would exhibit more attachment-type behaviors than fathers who had neither experience. A group of 48 fathers with an age range of 18 to 39 were studied. About three-quarters of these men were experiencing a first birth. A majority were blue collar workers and all but three of the fathers were in their first marriage. Each father was approached within 24 hours of delivery and consent was obtained for an observer to be present mainly after the evening feeding. Raters were blind to the major independent variables during observations. Both proximal and distal attachment variables were examined. Separate one-way ANOVAS indicated that the highest inspection, verbalization, and composite scores were for fathers who were present at delivery whether or not they had attended classes. Lowest scores were for fathers who were not at classes or delivery. Attendance at prenatal classes was not associated with father-to-infant behavior as strongly as presence at delivery was. The relationship between father's behaviors and a number of other variables was examined using a stepwise multiple regression analysis. Other than presence at delivery, the only other significant variable was infant state 1 (sleeping). The hypothesis that more attachment-type behaviors would be expressed by fathers who were present at the infant's birth were only partially supported. No evidence supported that hypothesis that more attachment-type behaviors would be expressed by fathers who attended prenatal 
classes than those who did not. Bowen and Miller stated in their conclusion that "it could be that fathers who were most interested in parenting were more likely to be present at delivery and were more likely to be verbally and visually interested in their newborns" (p. 77).

\section{Paternal Involvement in Infant Care}

Despite numerous examples that nurturing fathers exist, little is known about how and why men increase their involvement with their infants. Many developmental psychologists have studied the effects of paternal nurturance on child development and the significance of the father's role in the infant's social interaction.

Tomlinson (1987) assessed 96 fathers in a study to determine the level and quality of paternal involvement in their infants' care and to measure interpersonal and situational factors associated with the levels of involvement. Couples were recruited from childbirth classes during the 24th-30th week of pregnancy and were sent a questionnaire pre-birth and at three months post-birth. Both the fathers' involvement and the mothers' perception of the fathers' involvement were measured. Results of the study indicated that "prior to fatherhood, the subjects had relatively little exposure to or confidence in their preparation to care for an infant" (p. 104). The more prepared a father perceived himself to be, the more likely he was to have a higher degree of involvement. The major limitation of the study was that the measurement relied upon recall and may not have presented an accurate estimate of the father's involvement. The authors suggested that reliability estimates could have been made using a correlation index of partner observation.

Rustica and Abbott (1990) studied 53 father-mother dyads, 95\% of which were 
white, and all of which were either married or cohabiting during the course of the study, for paternal role performance. Paternal role performance, in this study, included the following predictors: normative expectations of appropriate paternal behavior, personal expectations regarding what the father believes he will do, expectations by the spouse, and prior learning of the role. Trained interviewers collected data at seven points from after birth until about two years later. One of the hypotheses of the study stated that fathers who have more prior learning experiences regarding the paternal role will perform more paternal role behaviors. Results of the study indicated that prior learning, operationalized as knowledge of child development and extent of parental modeling experiences, was not strongly related to paternal role performance. Although this result appears to contradict previous research showing a positive relationship between prior learning and current role performance, the authors stated that the result was probably due to poor measurement of these variables in this study. The authors suggested that this was a limitation of the study, and that further work was needed to improve the reliability and validity of this measurement (Rustica and Abbott, 1990).

Tiller's (1995) research attempted to determine, through a nonrandomized, longitudinal, descriptive study, whether fathers' interactions with their children from pre-birth to one year of age changed the fathers' parenting attitudes. She studied both experienced and first-time fathers, ages 16-44. Data were collected pre-birth, at three months, and at one year of age. The Adult-Adolescent Parenting Inventory was used to measure these changes. One of the resulting nursing implications was that fathers need more information about what to expect during the first three months of life with an 
infant. Information about normal growth and development, made available to fathers for future reference, would help fathers know what to expect and, in turn, how they could most effectively respond to their infants.

\section{$\underline{\text { Summary }}$}

The developing parent-infant relationship was identified throughout the literature by a number of confusing terms such as acquaintance, attachment and bonding. Some researchers such as Ainsworth (1973) and Bowlby (1977) used the terms interchangeably with their focus on attachment from infant to mother. Klaus and Kennell (1976) stated that bonding was the affectional tie from parent to infant and attachment as the affectional tie from infant to parent. Some of the confusion was eliminated when Gay (1981) presented a framework which defined attachment and bonding as a mutual relationship to which mother and child both contribute.

The literature review supports the view that further research into the area of fathering, in general, is needed. Research regarding mothering, maternal-infant bonding, and the effects of interventions to facilitate satisfactory maternal-infant relations was found prior to the 1960's. These areas have been a frequent topic of research for about four decades. Research regarding fathering, father-infant acquaintance/attachment, and interventions to facilitate satisfactory paternal-infant relations has only been studied in some depth for the last 20 years and has never received the interest that maternal bonding has received. Research regarding the effects of attending childbirth classes on fatherinfant bonding was found to be minimal. Nichols (1993) stated that "since fathers are permitted and encouraged to be active participants during pregnancy and childbirth, the nature of the experience from the father's perspective needs to be explored" (p. 99). 
The changing role of the father within the family and the increased interest fathers themselves have shown in sharing childrearing have produced a recent proliferation of research regarding the area of fathering. Many gaps still remain, and there are untouched areas left to explore.

\section{Theoretical Framework}

Gay's Conceptual Framework of Bonding (1981) was used as the basis for this study. Gay found that the terms referring to attachment and bonding were often used almost interchangeably and developed the framework to connect the interrelated concepts of acquaintance, attachment, and bonding. Gay (1981) stated that, "Conceptual clarity is a prerequisite to the identification of nursing actions that may enhance, or least not impede, the bonding process between parents and their children" (p. 440).

Much of Gay's supporting data came from studies of mothers and children, but she has encouraged those who use the framework to view bonding as a "human potential that is not limited by sexual gender or societal role assignments" (p. 440). She suggested that the concepts of acquaintance, attachment, and bonding should be viewed as gradual and occasionally overlapping processes.

Newcomb (1961) stated that acquaintance is the foundation of all subsequent relationships and that an opportunity is required for a two-way interaction between responding individuals. Three areas contributing to acquaintance are gaining information, assessing the infant's attitude, and continuing to collect data. Gaining information might be through any of the senses, and Gay stated that fathers most often gain information through visual and tactile behaviors. Fathers have been noted to assess 
the infant's attitude early in the period of acquaintanceship. Gay noted that a father's interpretations of the infant's behavior and his expressions of feeling for the infant were indicative of assessing infant attitudes. It is anticipated that when the father is successful in gaining information about the infant and developing a positive parent-infant relationship, continued data collection will allow an attachment to the infant to form.

Gay (1981) defined attachment as a "gradual, continuing, reciprocal process that occurs between individuals and incorporates the components of the acquaintance process" (p. 441). Gay noted that the initial studies regarding attachment were unidirectional in focus. They studied the attachment from the child to the main caretaker. Focus was on how and when the child forms this attachment. Gay included Ainsworth's six criteria crucial to attachment formation including specificity, duration, level of maturity, affective implications, active proximity seeking/maintenance behaviors, and learning.

Gay (1981) defined bonding "as a gradual, continuing, reciprocal process that incorporates the processes of acquaintance and attachment and links two individuals in a coordinated, constructive, social relationship" (p. 442). Sociological and psychological literature has implied that bonds forms after acquaintance and attachment occur. These bonds develop through many overlapping opportunities for learning and not during one specific brief and critical time period.

Gay developed a schematic model of the bonding process (See Figure 1) to permit conceptualization of its progression. Early in the relationship, two persons who are not acquainted serve as initial stimuli initiating the beginning of acquaintance. A reciprocal response $(\mathrm{R})$ reinforces the stimulus $(\mathrm{S})$ and allows the acquaintance process to continue 
through attachment and then bonding.

\section{Figure 1}

Gay's Schematic Model of the Bonding Process
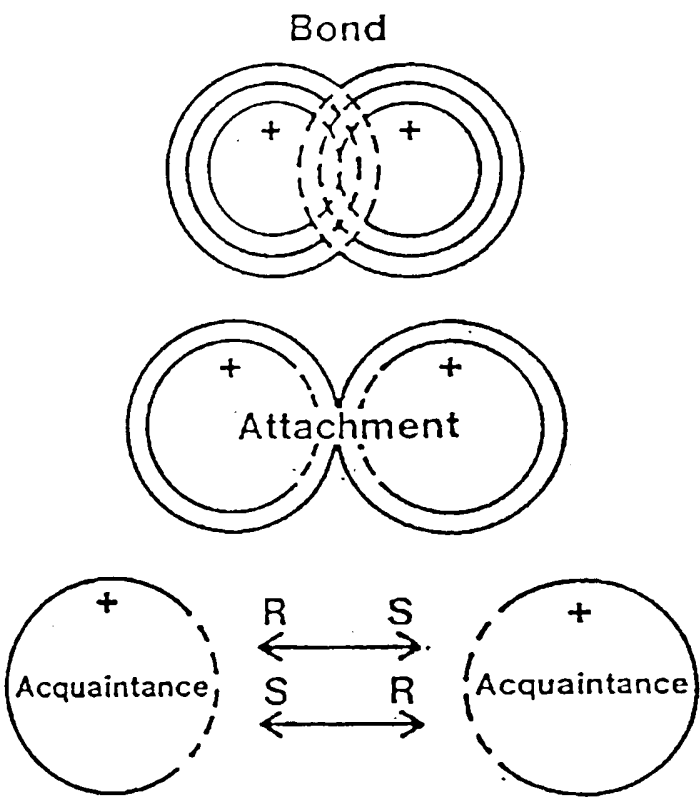

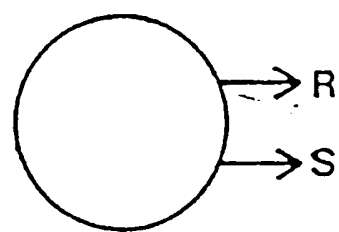

Person

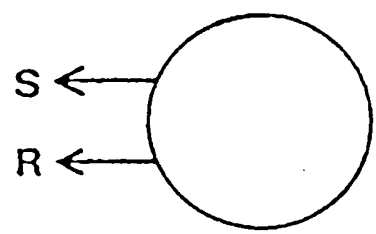

Person

Gay stated that attachment incorporates the acquaintance process, is lengthier in its development, and is more enduring than acquaintance. Bonds can occur only after development of attachment, and require even more time and more cognitive development than attachment. Although acquaintance and attachment may result in negative affect and end with termination of the process, bonds permit only positive affect and are not terminated. 
The nurse, in selecting measures to promote bonding, must be aware of where the parents currently are in the total process. One of the nursing actions suggested by Gay to contribute to parent-infant bonding is to promote opportunities for parent-infant acquaintance. With the advent of ultrasonography, this acquaintance can be initiated even before delivery. Prenatal education classes are another means of allowing fathers to gain information about their unborn infants. At the time of delivery, the nurse can facilitate behaviors of gaining information and proximity seeking by encouraging both visual and tactile activities between the parents and the infant. By establishing an early and continuing acquaintance between parents and their infants through attendance at prenatal classes and presence at delivery, attachment and, consequently, bonding can be encouraged. 


\section{Chapter 3}

\section{Methodology}

This chapter describes the research design and the data collection tools. The method of data collection and method of data analysis used in the study are also addressed.

\section{$\underline{\text { Research Design }}$}

This study was a retrospective, ex post facto design in which the research was conducted after the variations had occurred in the natural course of events. The study compared the significance of prepared childbirth class attendance and presence at the birth of the infant with father-infant acquaintance and attachment. This involved comparing groups of fathers who did and did not participate in prepared childbirth classes and also fathers who were and were not present at the infant's birth. A cross-sectional approach, involving data collection at one point in time, was used. Data was collected, employing a Likert scale, only once for each of the subjects rather than longitudinally over time.

\section{Sample}

The target population for this study was first-time biological fathers who were living with the infant's biological mother. The accessible population was a convenience sample of first-time biological fathers living with the infant's biological mother recruited during the three or four month well-baby visit at two private and one clinic based pediatric offices. Every father accompanying his infant to the three or four month visit, whether with the mother or by himself, was recruited to participate in the study. If the father did not accompany the mother to the visit, the father was recruited by sending the 
materials and an addressed, stamped envelope home with the mother. Sample size was determined by the number of fathers who participated over a four month period. An attempt to reduce sampling bias was made by using both private and clinic based offices, and by recruiting fathers during daytime, evening, and weekend office hours. Thirty first-time fathers returned completed sets of questionnaires.

\section{Protection of Human Subjects}

Approval for the study was received from the University Research Council. All potential study participants were instructed in the cover letter about the purpose of the study, and that no names or identifying marks would be placed on the research materials. Potential participants were advised that inclusion in the study was voluntary, and that their decision whether or not to participate would not make a difference in their infants' care (See Appendix B). To insure that participants would remain anonymous, there were no codes indicating from which office a packet was received. Study materials will be kept in a secure location for the next three years and then destroyed.

\section{$\underline{\text { Data Collection Tools }}$}

Data collection tools consisted of the Demographic Data Form (See Appendix C) created by the author, including demographic and other pertinent information about the study participants, and Leifer's How I Feel About My Baby Now questionnaire (See Appendix D). The Leifer, How I Feel About My Baby Now (FAB), tool is an Likert scale containing eight items and measuring father-infant attachment. It has been considered a relevant test because of its content validity, appropriateness for administering from birth over infancy, the mix of positive and negative statements, and 
ease of completion. Items are checked by the study participant in one of four columns marked often, sometimes, rarely and never. Reliability scores for the FAB questionnaire have ranged from .66 to .81 (Leifer, 1977). Beck (1998) stated that the FAB tool has been used to assess paternal as well as maternal-infant attachment in a number of studies.

\section{Data Collection Procedure}

Research materials consisted of a cover letter (See Appendix B), indicating the purpose of the study, as well as a demographic survey and the FAB questionnaire. After obtaining permission from the two offices and the clinic, the receptionist at the front desk was given a supply of the cover letters and questionnaires. Each father who came to the office/clinic with his infant for a three or four month well-baby visit was recruited for the study and given the cover letter and the questionnaires. The data were collected from the fathers in self-reports while waiting for the doctor or nurse practitioner and was returned to the front desk before leaving the office. If the father was unable to complete the questionnaires while waiting, a stamped, addressed envelope was provided for mailing. When the father was not present at the visit, the same materials plus a stamped, addressed envelope were given to the mother with a request for her to give the materials to the father when she arrived at home.

The researcher picked up completed questionnaires weekly. Fathers who were recruited at the three month visit were listed so they were not recruited again at four months. A returned questionnaire and demographic data sheet indicated a willingness to participate in the study.

Method of Data Analysis

Research data were collected regarding the effect of the variables of attending the 
classes and the birth, attending only the classes, attending only the birth, or doing neither upon the variable of father-infant acquaintance/attachment. Demographic characteristics of the fathers were examined by describing their frequency of occurrence and percentage of the total population. T-tests were performed on all eight FAB items related to each of the demographic characteristics. A one-way ANOVA was used to analyze the scores on the FAB questionnaire in relationship to the demographic characteristics. 
Chapter 4

Results

Study results are described in this chapter. Demographic characteristics of the study respondents are presented along with the answers to specific items from the demographic data sheets. The total scores and scores on the individual items obtained from study participants on the How I Feel About my Baby Now (FAB) tool were analyzed using descriptive statistics, t-tests, and a one-way ANOVA.

\section{Data Collection Response}

After receiving permission to distribute test materials in the three participating facilities (See Appendix A), a total of 90 sets of questionnaires and stamped return envelopes were distributed. Over a four-month period, 30 responses were received. Total group response was $30 \%$. No responses were excluded due to identifying information or inadequate information. Of the total of 30 responses, only three were received in the mail.

\section{Demographic Data}

Descriptive data for the fathers in the study were obtained from the Demographic Data Form (See Appendix C). The sample of 30 fathers included $36.3 \%$ in the $31-40$ year old age group. The next largest representation was 30\% in the $21-30$ year old age group. Fathers who were 41-50 years of age responded at 20\%, and there were no respondents in the 51-60 year old age group.

Despite the diverse ethnic representation of the offices and clinic in which the surveys were distributed, the majority of the total group respondents were Caucasian. Caucasian fathers comprised $90 \%$ of the respondents, with the next largest group being 
Asian fathers at 6.7\%. African-American fathers responded at 3.3\%, and there were no Hispanic respondents.

Table 1

Characteristics of Total Sample by Age and Race

$\begin{array}{llll}\text { Variable } & \underline{\mathrm{f}} & \% & (\underline{\mathrm{N}}=30)\end{array}$

$\underline{\text { Age }}$

Under 21

21-30

9

30.0

$31-40$

14

36.3

41-50

6

20.0

$51-60$

0

0.0

Race

Caucasian

African-American

1

Asian

6.7

Hispanic

0

0.0

Other

0

0.0

$\underline{\mathrm{f}}=$ frequency. $\quad \%=$ percent.

Table 2 presents the level of education, occupation, and marital status of the study respondents. Results revealed that $26.7 \%$ of fathers responding were high school graduates. Fathers with baccalaureate degrees comprised $23.3 \%$ of the participants, and 
those with master's degrees comprised $20 \%$. Thirty percent of the respondents answered other in the category of level of education. Examination of the Demographic Data Forms themselves revealed that in these cases the occupation of the respondent was usually professional. This indicates that "other" was usually post-master's degree education, but these results were not considered as such statistically.

The next demographic characteristic represented in Table 2 is the occupation of the respondents. The majority of the respondents, $46.7 \%$, classified themselves in the professional category. The next largest representation was white collar workers at $40 \%$, and blue collar workers comprised $13.3 \%$ of the sample. There were no unemployed respondents.

The last characteristic represented in Table 2 is marital status. The majority of fathers responding, 93.3\%, identified themselves as married. An equal percentage of respondents were single and divorced at 3.3\%.

Table 2

Characteristics of Total Sample by Education, Occupation, and Marital Status

Variable

$\underline{f}$

$\% \quad(\underline{\mathrm{N}}=30)$

\section{$\underline{\text { Level of Education Completed }}$}

Eighth grade

High school graduate 
Master's degree

Other

Occupation

Professional

14

12

4

0

9

30.0

White collar

Blue collar

Unemployed

$\underline{\text { Marital Status }}$

Married

Single

Divorced

Widowed

28

1

1

3.3

0
46.7

40.0

0.0

$\underline{\mathrm{f}}=$ frequency. $\quad \%=$ percent.

\section{$\underline{\text { Research question \#1 }}$}

Research question \#1 asked, "Is there a relationship between the variable of the father's presence at the infant's birth and the variable of father-infant acquaintance/attachment at three to four months of age?". Fathers responded 'yes' or 'no' to the question regarding presence in the room at their baby's birth on the Demographic Data Form (See Appendix C). The vast majority of the respondents, $96.7 \%$, answered that they were present at the time of delivery. It was noted that the one father not present at delivery also did not attend a series of prepared childbirth classes. 
The sample was too homogeneous to evaluate statistically, and thus the first research question could not be answered.

Table 3

$\underline{\text { Fathers Present at Birth }}$

$\begin{array}{lll}\text { Present } & \text { f } & \%\end{array}$

\begin{tabular}{ll} 
Yes & 29 \\
\hline
\end{tabular}

$\begin{array}{lll}\text { No } & 1 & 3.3\end{array}$

$\underline{\mathrm{f}}=$ frequency. $\quad \%=$ percent.

\section{Research Question \#2}

Research question \#2 asked, "Is there a relationship between the variable of the father's participation in an entire series of prepared childbirth classes and the variable of father-infant acquaintance/attachment at three to four months of age?". Fathers were asked to respond 'yes' or 'no' on the Demographic Data Form (See Appendix C) regarding whether they had or had not attended an entire series of prepared childbirth classes with the infant's mother. Responses indicated that of the two groups, nineteen, or $63.3 \%$ of the fathers did attend an entire set of prepared childbirth classes. Eleven fathers or $36.7 \%$ of the total did not attend classes.

Table 4 summarizes responses to the question regarding attendance at an entire series of prepared childbirth classes. 
Table 4

Fathers Attending Childbirth Classes

Attended class

$\underline{f}$

$\%$

Yes

19

63.3

No

11

36.7

$\underline{\mathrm{f}}=$ frequency. $\quad \%=$ percent.

Fathers were also asked to mark their responses on the How I Feel About My Baby Now $(F A B)$ tool (See Appendix D). Scores on the negatively phrased items were reverse coded for some tests. Statistical analysis of the frequency of all variables on the FAB tool indicated that, in general, total scores for all fathers in the study were high $(\underline{M}=3.54, \underline{S D}=0.30)$ whether or not they had attended childbirth classes.

Next, t-tests were performed on the individual items on the FAB tool with the respondents divided into a group who attended the childbirth classes and a group who did not attend the classes. Results indicated that everyone in the group taking the classes often felt tenderly towards their babies $(\underline{\mathrm{M}}=4.00, \underline{\mathrm{SD}}=0.00)$, but not significantly more than the group not taking the classes $(\underline{\mathrm{M}}=3.91, \underline{\mathrm{SD}}=0.30)$. No fathers in either of the two groups responded to any other choice than 'never' when asked if they felt hatred towards their babies $(\underline{\mathrm{M}}=1.00, \underline{\mathrm{SD}}=0.00)$.

The FAB item "I feel angry at my baby" produced the most significant results when statistically compared with the other seven FAB items (See Table 5). The fathers who attended childbirth classes felt significantly more angry towards their babies 
$(\underline{\mathrm{M}}=1.58, \underline{\mathrm{SD}}=0.84)$ than the fathers who did not take the classes $(\underline{\mathrm{M}}=1.09$,

$\underline{\mathrm{SD}}=0.30$ ). This was statistically significant with a p-value of 0.030 . However, scores

were low in both groups with $63 \%$ of the fathers taking the classes and $91 \%$ of the fathers not taking the classes saying they were never angry with their babies.

Table 5

Analysis of FAB Items by Class Attendance

\begin{tabular}{|c|c|c|c|c|c|c|}
\hline \multirow[b]{2}{*}{ FAB } & \multicolumn{2}{|c|}{ Yes $(\underline{n}=19)$} & \multicolumn{2}{|c|}{ No $(\underline{\mathrm{n}}=11)$} & \multirow[b]{2}{*}{ t-value } & \multirow[b]{2}{*}{$\mathrm{p}$-value } \\
\hline & $\underline{\mathrm{M}}$ & $\underline{\mathrm{SD}}$ & $\underline{\mathrm{M}}$ & $\underline{\mathrm{SD}}$ & & \\
\hline Total & 3.53 & 0.30 & 3.55 & 0.33 & -0.12 & .906 \\
\hline \multicolumn{7}{|l|}{$\underline{\text { Items }}$} \\
\hline Tenderly & 4.00 & 0.00 & 3.90 & 0.30 & 1.33 & .341 \\
\hline Annoyed & 2.00 & 0.82 & 2.00 & 0.78 & 0.00 & 1.000 \\
\hline Neutral & 1.33 & 0.59 & 1.36 & 0.67 & -0.13 & .904 \\
\hline Hatred & 1.00 & 0.00 & 1.00 & 1.00 & -- & -- \\
\hline Angry & 1.58 & 0.84 & 1.09 & 0.30 & 1.85 & $.030 *$ \\
\hline Giving & 3.84 & 0.38 & 3.73 & 0.47 & 0.74 & .496 \\
\hline Playful & 3.79 & 0.42 & 3.73 & 0.47 & 0.38 & .719 \\
\hline Drained & 2.47 & 0.84 & 2.55 & 1.13 & -0.20 & .857 \\
\hline
\end{tabular}

$\underline{\mathrm{M}}=$ mean. $\quad \underline{\mathrm{SD}}=$ standard deviation.

${ }^{*} \underline{p}<.05$. Note. Dashes indicate the $t$-value and $p$-value were not estimated. 
$\underline{\text { Research Question \#3 }}$

Research question \#3 asked, "How do demographic variables such as age, race, level of education, occupation, and marital status compare with acquaintance/attachment at three to four months of age?". All eight FAB items were statistically tested comparing them with the variables of age, race, level of education completed, occupation and marital status. T-tests comparing all demographic variables with the eight $\mathrm{FAB}$ items revealed statistical significance in only one area (See Table 6).

When groups were separated according to age, the fathers in the demographic group 30 years of age and younger all answered often to feeling playful towards their babies $(\underline{\mathrm{M}}=4.0, \underline{\mathrm{SD}}=0.00)$. This was significantly higher than the older fathers, more than 30 years of age $(\underline{\mathrm{M}}=3.65, \underline{\mathrm{SD}}=0.49)$. Pooled variance estimate revealed 28 degrees of freedom, with a p-value of .005 .

Table 6

$\underline{\text { F Feel Playful FAB Item Analyzed by Age }}$

\begin{tabular}{lccccccc}
\hline \multirow{2}{*}{ Item } & \multicolumn{2}{c}{$(\leq 30)$} & & \multicolumn{2}{c}{$(>30)$} & & \\
& $\underline{\mathrm{M}}$ & $\underline{\mathrm{SD}}$ & & $\underline{\mathrm{M}}$ & $\underline{\mathrm{SD}}$ & t-value & $\mathrm{p}$-value \\
\hline Total & 3.52 & .314 & 3.54 & .307 & -.19 & .855 \\
Playful & 4.00 & 0.00 & 3.65 & .489 & 3.20 & .005 \\
\hline
\end{tabular}

$\underline{\mathrm{M}}=$ mean. $\quad \underline{\mathrm{SD}}=$ standard deviation.

In addition to the t-tests, a one-way ANOVA was used to test all eight FAB items comparing them to the demographic variable of education. There was found to be no significant difference in the respondents scores relative to education. 


\section{Chapter 5}

\section{Discussion}

This chapter will explain the study findings and limitations. Implications for future research and nursing practice will also be discussed.

Demographic Characteristics of the Study Participants

A convenience sample of first-time fathers living with the mothers of their babies was recruited at the infant's three-four month well-baby visit. Of the 30 study respondents, the majority, (36.3\%), were in the $31-40$ year old age group, and the next largest group was 30\% in the $21-30$ age group. Caucasian fathers comprised $90 \%$ of the respondents. All study respondents were at least high school graduates, and $43.3 \%$ had attained the bachelor or master's degree level. All participants were employed, and the majority, $(46.7 \%)$, listed themselves as professionals. The largest segment of the fathers in the study were married $(93.3 \%)$.

Pooling the two largest groups of subjects by age, it is noted that $66.3 \%$ of the respondents were 21-40 years of age. This is an appropriate percentage of fathers in this age group, but it might have added important statistical information to the study if there had been a greater number of adolescent fathers.

With such a large percentage $(90 \%)$ of Caucasian fathers and $86.7 \%$ employed in either professional or white collar occupations, study results may reflect a cultural bias of white middle and upper-class society. These subjects are also more likely to have been exposed to the research process in the past, and thus more likely to agree to participate. However, no references were found in the literature that compared father-infant relationships and any of the demographic characteristics included in this study. 


\section{$\underline{\text { Results of Research Question \#1 }}$}

Research Question \# 1 asked, “Is there a relationship between the variable of the father's presence at the infant's birth and the variable of father-infant acquaintance/ attachment at three to four months of age?". Of the 30 respondents, only one was not present at the infant's delivery. Because $96.7 \%$ were present, the sample was too homogeneous to evaluate statistically.

\section{$\underline{\text { Results of Research Question \#2 }}$}

Research Question \#2 asked, "Is there a relationship between the variable of the father's participation in an entire series of prepared childbirth classes and the variable of father-infant acquaintance/attachment at three to four months of age?". The majority of the sample, $(63.3 \%)$, did attend the childbirth classes. Scores on the FAB tool indicated that everyone in the group taking the classes often felt tenderly towards their babies, but not significantly more so than those not taking the classes.

Miller and Bowen (1982) stated that attendance at prenatal class was not associated with father-to-infant behavior as strongly as presence at delivery was. Since all but one father in this study were present at delivery, this study may also support that finding. According to Gay's Conceptual Framework of Bonding (1981), opportunities for acquaintance lead to formation of attachment. Active proximity seeking behaviors on the part of the fathers may have influenced presence at delivery. Again, since only one father in the study did not attend the delivery, almost all were afforded this early acquaintance opportunity.

The FAB item "I feel angry at my baby" proved to be the most statistically 
significant when compared to the other seven FAB items on the tool. Fathers who attended childbirth classes felt significantly more angry at their babies than the fathers who had not $(\underline{p}=0.03)$. Traditional childbirth classes include information regarding the development of the fetus, physiology of labor, and comfort and support measures fathers can use in assisting the mother during labor and delivery. Prospective parents learn about physical care of the newborn including infant stimulation. In addition, many opportunities are provided for parents to share feelings, concerns, and misconceptions related to childbirth and parenthood. Childbirth educators encourage parents to verbalize and share thoughts about how their lives will change, and they validate parents' feelings that new stresses will be present. This may allow parents to feel freer to express their feelings, both positive and negative. Parents not attending the classes have not had this opportunity and may feel less comfortable with the expression of negative emotions. None of the fathers, however, answered anything other than 'never' to the statement regarding feelings of hatred towards their babies. Anger is a more muted and short-term emotion than hatred, and would be more common to experience when the stresses involved in caring for infants three or four months old are encountered.

Gay’s Conceptual Framework of Bonding (1981) suggests that opportunities for gaining information facilitate acquaintance. Those fathers who attended prepared childbirth classes gained a wealth of information including information on an emotional level. That information may have allowed those fathers to be more expressive about their feelings than the fathers not attending the classes.

\section{$\underline{\text { Results of Research Question \#3 }}$}

Research question \#3 asked, "How do demographic variables such as age, race, 
level of education, occupation, and marital status compare with acquaintance/attachment at three to four months of age?". After statistically comparing all eight FAB items with the variables on the Demographic Data Sheet, the only significant finding was that fathers in the group 30 years of age and younger all answered often to feeling playful towards their babies. This was significantly higher than for the fathers more than 30 years of age. A literature search revealed no studies related to age of the fathers and their feelings of playfulness with their infants.

\section{$\underline{\text { Limitations }}$}

Use of a convenience sample limited findings to this sample and may not have shown a normal distribution. An attempt was made with the Demographic Data Form to control for some of the extraneous variables, but there are others which may have affected study results.

Sample size was a limiting factor in the study. One of the offices approached to be a participating facility felt the How I Feel About My Baby Now (FAB) tool might be intimidating to their clientele and declined participation. In the three participating offices, the immediate liaison between the researcher and the prospective study participants was the receptionist. Opportunities for requesting a potential candidate were often missed when the office was busy. The author felt the need in the later months of the study to be present in the office to be sure opportunities for participation were not missed. When prospective participants requested to take the study materials home to complete or when mothers of infants took the materials home to the fathers, return rate was low. 
The goal for the size of the sample was to receive a return rate adequate to perform statistical analysis among four groups, those attending and not attending childbirth classes and those present and not present for delivery, in relationship to each of the items on the FAB tool. The return rate of the data sheets and tools did not permit this. Of the 30 respondents, only one had not been present at the infant's birth. This made any statistical analysis and discussion of research question \#1 impossible. It also limited results in research question \#2 almost to the level of a pilot study.

The sample group was $90 \%$ Caucasian. The remaining $10 \%$ included AfricanAmerican and Asian participants, but no Hispanic participants. Inclusion into the study of facilities whose population is primarily minority groups might assist in recruiting a more ethnically diversified group of respondents. The occupations of the study participants were $46.7 \%$ professional as opposed to $13.3 \%$ blue collar workers. Recruiting a greater number of participants from clinics rather than private pediatrics offices also could yield a larger sample from the other occupational categories.

Other variables that could not be controlled may have influenced the study. One of these is the fact that fathers who are already more attached to their infants might be more inclined to return a tool which relates to their feelings about their babies. There is also possibility that more tools were returned by fathers with professional occupations, (46.7\%), since they are more likely to have had experience with research studies.

\section{Implications for Future Research}

Since research regarding father-infant relationships is almost a decade behind research regarding the relationship of the mother and infant, there continues to be a need for continued study in this area. Research should be expanded to include the effects of 
some of the variables in relationship to father-infant acquaintance and attachment. No past studies were found comparing the father's age, occupation, race, or education with father-infant attachment.

A more significant number of studies were found comparing presence at delivery and father-infant attachment than studies comparing childbirth class attendance and father-infant attachment. Nurses teaching these classes are in a prime position to conduct related and possibly longitudinal research. The fact that $63.3 \%$ of the respondents in this study had attended childbirth classes demonstrates that there is a large accessible population for study.

Research instruments which relate to fathers and their infants during the postpartum period are few in number, and the newest of these is a 1985 instrument revised in 1989 (Beck, 1998). Of the two available research tools specifically relating to how fathers view their newborns, the first was developed in 1971 and the tool used in this study was developed in 1977. A need exists for an updated tool to measure father-infant acquaintance/attachment in future studies.

\section{$\underline{\text { Recommendations for Nursing Practice }}$}

Nurses and nurse practitioners, as health care providers in the area of infant and child health, are in constant contact with parents from conception of the infant through childhood. The nurse has the opportunity at a number of points along this continuum to positively affect the eventual father-infant bonding process by providing opportunity for acquaintance and attachment to the infant (Gay,1981). Nursing must be aware of the relationship between opportunity and attachment. The nurse practitioner should take 
advantage of the "sensitive periods" (Klaus and Kennell, 1982) fathers are experiencing as they become acquainted with first the fetus and then the newborn to assist them in forming an attachment that will promote eventual bonding (Gay, 1981).

Nurses involved in office and hospital-based obstetric nursing as well as in nurse midwifery should continue to encourage fathers to take the opportunity to attend childbirth classes, be present at delivery, and, in fact, be involved in each aspect of the pregnancy and delivery as possible. Fathers must also be encouraged to ask questions and to express and share feelings common to new fathers. Since many new fathers are unaware that they may have feelings and frustrations in common with other new fathers, it would be advantageous to make informal group discussion available to new fathers as well as new mothers. Perhaps hosting one prenatal class session "for fathers only" would provide an opportunity to share feelings and misgivings.

When the father is present at the delivery, the nurse should take an active role in providing opportunity for acquaintance and attachment. It is not enough that the father is simply in the room, but he should be encouraged to hold, make eye contact with, touch, and examine the newborn. When the infant is moved from the warmer back to the mother, the father should be the one to carry the baby. Measures to promote parentalinfant eye contact, such as keeping the room lighting low and delaying the instillation of eye medications, should be taken by the nursing staff. Mothers and fathers should be provided time to be alone with the newborn following delivery.

It is hoped that studies such as this one will enlarge the knowledge base of nurses working with new families. The nurse's sensitivity, empathy, and support of the father are essential and may contribute positively to father-infant acquaintance and attachment. 


\section{References}

Ainsworth, M. (1969). Object relations, dependency, and attachment: A theoretical view of the infant mother relationship. Child Development, 40, 969-1025.

Ainsworth, M. (1973). The development of infant-mother attachment.

In B. M. Caldwell \& H. N. Riccuiti (Eds.), Review of child development research. Chicago: University of Chicago Press.

Beck, C. T. (1998). A review of research instruments for use during the postpartum period. Maternal Child Nursing, 23 (5), 254-261.

Bowen, S. M. and Miller, B. C. (1980). Paternal attachment behavior as related to presence at delivery and preparenthood classes: A pilot study. Nursing Research, 29 (5), 307-311.

Bowlby, J. (1969). Attachment and loss. Volume I: Attachment. New York: Basic Books, Inc.

Bowlby, J. (1977). Making or breaking of affectional bonds: Aetiology and pathology in light of attachment theory. British Journal of Psychiatry, 130, 201-210.

Bowlby, J. (1980). Attachment and loss. Volume III: Loss. New York: Basic Books, Inc.

Brazelton, T. B. (1981). On becoming a family. New York: Delta.

Coffman, S. (1992). Parent and infant attachment: Review of nursing research 1981-1990. Pediatric Nursing, 18 (4), 421-425.

Cox, M. J., Owen, M. T., Henderson, V. K., and Margand, N. A. (1992). 
Prediction of infant-father and infant-mother attachment. Developmental Psychology, 28

(3), 474-482.

Ferketich, S. L. and Mercer, R. T. (1995). Paternal-infant attachment of experienced and inexperienced fathers during infancy. Nursing Research, 44, (1), 31-37.

Garbino, J. (1993). Essay: Reinventing fatherhood. Families in Society: The Journal of Contemporary Human Services, January, 51-54.

Gay, J. (1981). A conceptual framework of bonding. Journal of Obstetric, Gynecologic and Neonatal Nursing, 10, 440-444.

Hall, W. A. (1994). New fatherhood: Myths and realities. Public Health Nursing, 11 (4), 219-228.

Henderson, A. D. and Brouse, A. J. (1991). The experiences of new fathers during the first three weeks of life. Journal of Advanced Nursing, 16 , 259-273.

Jordan, P. L. (1990). Laboring for relevance: Expectant and new fatherhood. Nursing Research, 39 (1), 11-16.

Klaus, M. H. and Kennell, J. H. (1976). Maternal-infant bonding. St. Louis: C. V. Mosby Co.

Klaus, M. H. and Kennell, J. H. (1982). Parent-infant bonding. St. Louis: C. V. Mosby Co.

Kunst-Wilson, W. and Cronenwett, L. (1981). Nursing care for the emerging family: Promoting paternal behavior. Research in Nursing and Health, 4, 201-211.

Lamb, M. E. (1986). The changing role of fathers. In M.E. Lamb (Ed.), The father's role: Applied perspectives. New York: John Wiley and Sons. 
Leifer, M. (1977). Psychological changes accompanying pregnancy and motherhood. Genetic Psychology Monographs, 95, 55-96.

May, K. A. (1982). Three phases of father involvement in pregnancy. Nursing Research, 31, 337-342.

Mead, M. (1949). Male and female. New York: William Morrow and Co.

Mercer, R. T. (1985). The process of maternal role attainment over the first year. Nursing Research, 34, 198-204.

Mercer, R. T. and Ferketich, S. L. (1990). Predictors of parental attachment during early parenthood. Journal of Advanced Nursing, 15, 268-280.

Miller, B. C. and Bowen, S. L. (1982). Father-to-newborn attachment behavior in relation to prenatal classes and presence at delivery. Family Relations, January, 71-78.

Nelson, S. (1985). Attachment theory. Nurse Practitioner, 10, 34-36.

Newcomb, T. (1961). The acquaintance process. New York: Holt, Rinehart, and Winston.

Nichols, M. R. (1993). Paternal perspectives of the childbirth experience. Maternal-Child Nursing Journal, 21 (3), 99-108.

Palkovitz, R. (1985). Fathers' birth attendance, early contact, and extended contact with their newborns: A critical review. Child Development, 56, 392-406.

Palkovitz, R. (1987). Fathers' motives for birth attendance. Maternal-Child Nursing Journal, 16 (2), 123-129.

Palkovitz, R. (1992). Changes in father-infant bonding beliefs across couples first transition to parenthood. Maternal-Child Nursing Journal, $20(3,4), 141-154$. 
Rubin, R. (1967). Attainment of the maternal role: Part I, processes.

Nursing Research, 16, (3), 237-245.

Rubin, R. (1984). Maternal identity and the maternal experience.

New York: Springer Publishing Co., Inc.

Rustica, A. and Abbott, D. A. (1990). Predicting paternal role enactment.

Western Journal of Nursing Research, 12 (2), 145-160.

Sandelowski, M. and Black, B. P. (1994). The epistemology of expectant parenthood. Western Journal of Nursing Research, 16 (6), 601-622.

Tiller, C. M. (1994). Fathers' parenting attitudes during a child's first year. Journal of Obstetric, Gynecologic, and Neonatal Nursing, 24 (6), 508-514.

Tomlinson, P. S. (1987). Father involvement with first-born infants:

Interpersonal and situational factors. Pediatric Nursing, 13 (2), 101-105.

Weaver, R. H. and Cranley, M. S. (1983). An exploration of paternal-fetal attachment behavior. Nursing Research, 32 (2), 68-72. 
Appendix A

Facility Participation Letter 
Susan D. Bernath, R. N., Master of Science Student, Florida International University School of Nursing is conducting research to study the correlation between fathers' participation in a series of prepared childbirth classes and attending the birth of the infant to father-infant bonding.

It is requested that your facility participate in gathering information from firsttime fathers who live with the mother of their infant. Information will be collected in the form of a demographic questionnaire and one brief Likert scale. It is hoped that these questionnaires can be completed at either the three or four month well-baby visit. Those fathers agreeing to participate would be given the questionnaires to complete while they wait for their infants to be seen by the physician or nurse practitioner or to take home with them to complete and mail back. Maximum time needed to finish all three items would be less than 15 minutes.

Questionnaires would be distributed over a four month period, and the researcher would pick up completed questionnaires weekly. The facility would be provided with an updated list each week so that fathers who participated at three months would not be recruited again at four months.

All information on the questionnaires will be strictly confidential and will be seen only by the researcher. If a report of the results is published, only information from the total group will appear.

Your facility's assistance would be invaluable, and results of the study will be shared at the conclusion. If at any time there are questions regarding the study, please contact Susan Bernath at 941-489-9421. 
Appendix B

Cover Letter and Information

For Father-Infant Study 


\section{COVER LETTER AND INFORMATION \\ FOR FATHER-INFANT STUDY}

My name is Susan Bernath, and I am a graduate student at Florida International University School of Nursing. I am studying the ways fathers get ready for the birth of their baby and their effect on the father after the baby's birth.

If you are a first-time father who lives with the mother of your baby, you will be asked to be a part of the study. If you agree, you will be asked to fill out a short informational questionnaire and to answer a short list of questions. Simply checking off the box that most closely shows your feelings can complete this list.

If you are part of the study, all information will be considered confidential. You will not be asked to put your name on the questionnaire. If a report of the results is made available to the public, only information about the total group will be used. Please fill out the questionnaire while you wait for your appointment and turn the completed questionnaires in to the front desk before leaving the office. If not enough time is available, you will be given an addressed, stamped envelope in which to send the survey back.

It is hoped that the information from this study will be helpful to fathers preparing for their babies' births in the future. Whether you are a part of the study or not is totally up to you. It will in no way make a difference in your infant's care.

If you have any questions, please contact Susan Bernath at 941-489-9421. Thank you for considering being part of the study. 
Appendix C

Demographic Data Form 


\section{DEMOGRAPHIC DATA FORM}

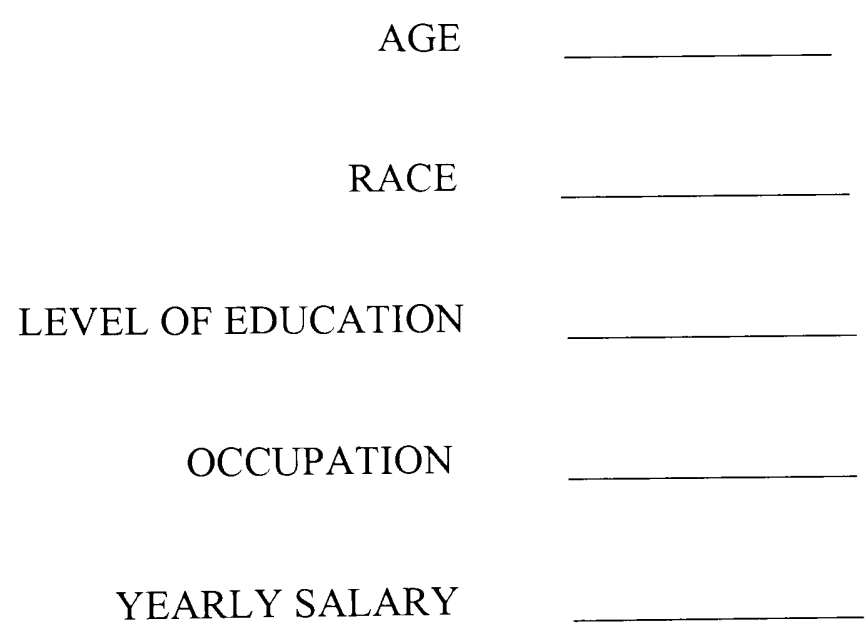

ATTENDED A FULL SERIES OF PREPARED CHILDBIRTH CLASSES WITH INFANT'S MOTHER

YES__ NO _ _

PRESENT IN THE ROOM AT YOUR BABY'S BIRTH YES NO NO 


\section{Appendix D}

How I Feel About My Baby Now 


\section{HOW I FEEL ABOUT MY BABY NOW}

Please check the box which most closely matches how you feel at the present.

\begin{tabular}{|l|l|l|l|l|}
\hline & OFTEN & SOMETIMES & RARELY & NEVER \\
\hline I feel tenderly towards my baby. & & & & \\
\hline I feel annoyed at my baby. & & & & \\
\hline I feel not one way nor the other. & & & & \\
\hline I feel hatred towards my baby. & & & & \\
\hline I feel angry at my baby. & & & & \\
\hline I feel giving towards my baby. & & & & \\
\hline I feel playful towards my baby. & & & & \\
\hline I feel drained by my baby. & & & & \\
\hline
\end{tabular}


Appendix E

Letter of Permission for Use of Bonding Model 
Appendix E

Letter of Permission for Use of Bonding Model 
Graen Bersatts

33266 Broadhuset Laepatir

oret Drugnsoctloreda 33919

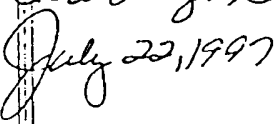

Dleas Syaw.

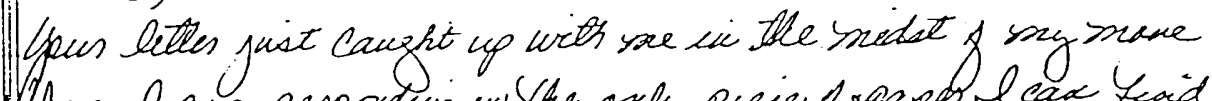

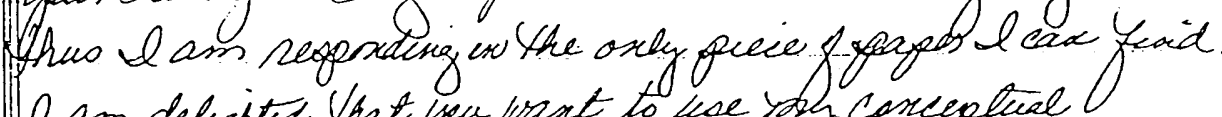
Lam deligited that you want to use ing concepluad

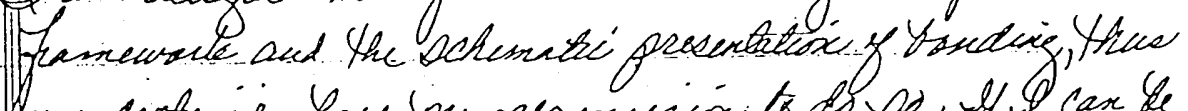

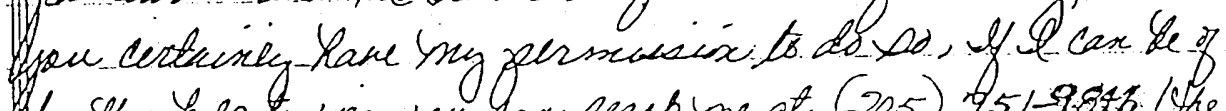

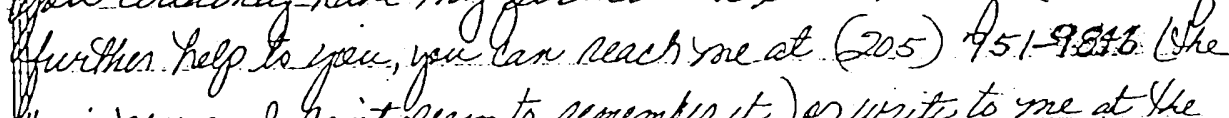

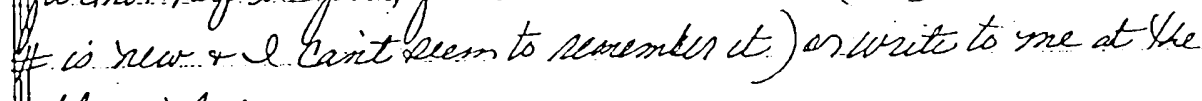
eddresodelow.

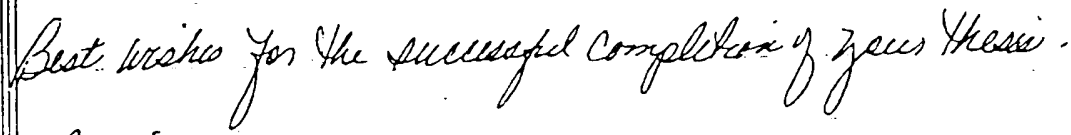

fincinty

panictempldre Lay, UN, ASB

415 calleve st n. Do,

Btartaelle, 910.35640

54 
Graen Bersatts

33266 Broadhuset Laepatir

oret Drugnsoctloreda 33919

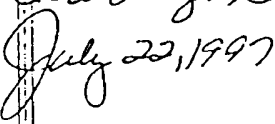

Dleas Syaw.

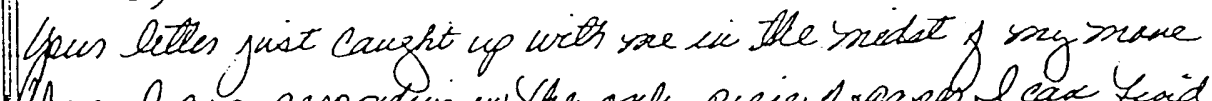

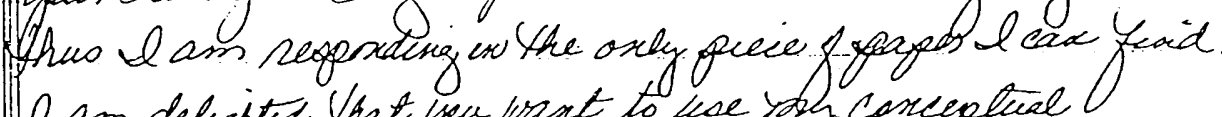
Lam deligited that you want to use ing concepluad

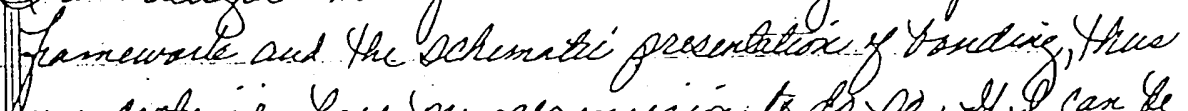

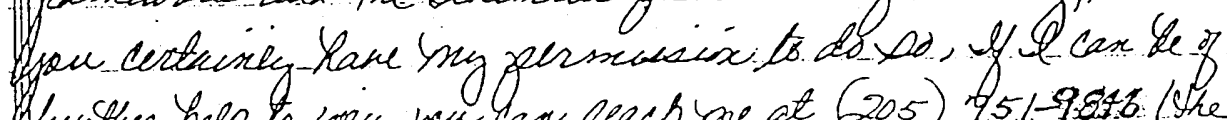

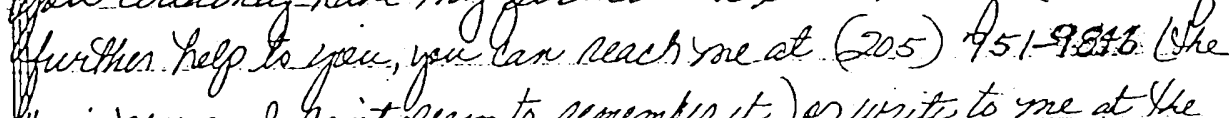

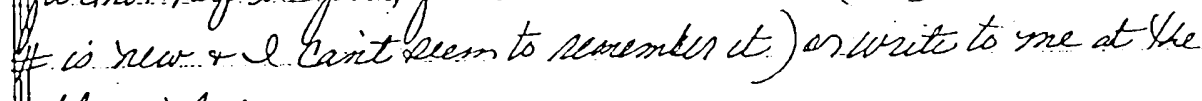
eddresodelow.

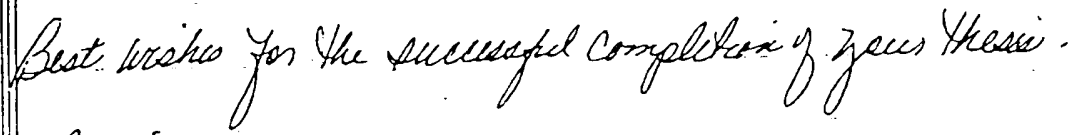

fincinty

panictempldre Lay, YN, ASB

415 calleve st n. Do,

Btartaelle, 910.35640

54 
Appendix F

Letter of Permission for Use of Attachment Tool 
$\frac{\text { IS P P }}{\text { Illinois School of Professional Psychology }}$

Chicago Campus

Two First National Plaza + 20 South Cark Street + Third Floor

Chicago, IL 60603

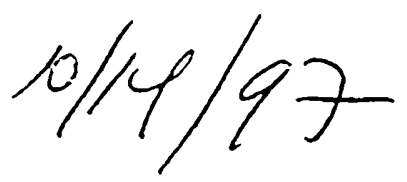

permission to cu ce the "Ito \& Feel At ut

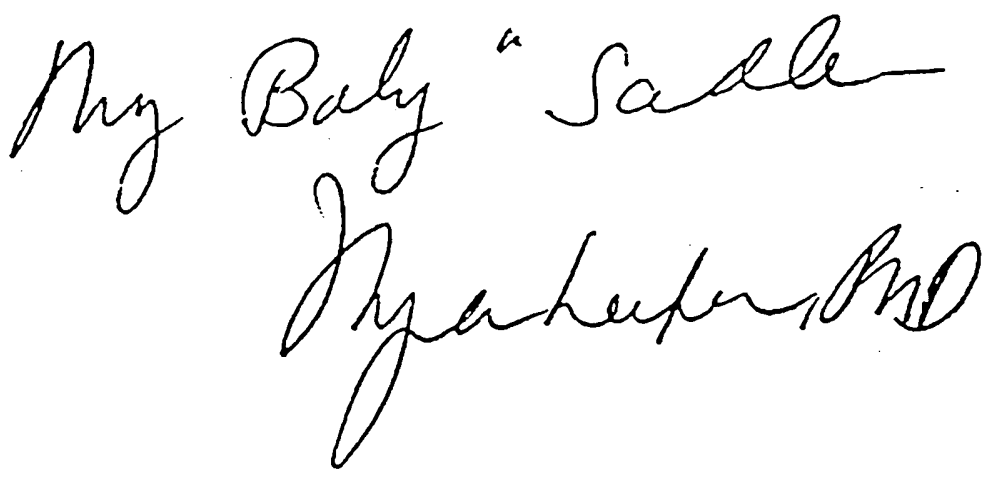

56 